\title{
RANCANG BANGUN GAME SUITCAKE BERBASIS ANDRODI DENGAN METODE ALGORITMA LINEAR CONGRUENT
}

\author{
Reno Supardi, Tommy Dwi Putra \\ Program Studi Informatika Fakultas Ilmu Komputer Universitas Dehasen Bengkulu \\ Jl. Meranti Raya No. 32 Kota Bengkulu 38228 Telp. (0736) 22027, 26957 Fax. (0736) 341139; \\ renosupardi00@yahoo.com, tommydputra@gmail.com
}

\begin{abstract}
Games are one type of entertainment that is played by everyone from the ages of children, young or old. Games are made with the intent and purpose so that the players become funny, happy, and can relieve stress. This research discusses the making of a game called SUITCAKE that uses the Algorithm Linear Congruent Method (LCM) with Android Studio software. the Algorithm Linear Congruent (LCM) is a method of rounding random numbers that are widely used in computer programs. This game ignores traditional game suits with the same rules plus several additional features that make this game suit modern. Android-based, which means this game can run on the Android platform and can be downloaded on Playstore.
\end{abstract}

Keywords: Game, Linear Congruent Method, Suit, Android.

Abstrak - Game adalah salah satu jenis hiburan yang disukai oleh semua orang dari kalangan usia anakanak, muda maupun tua. Game dibuat dengan maksud dan tujuan agar para pemain menjadi senang, bahagia dan bisa menghilangkan stress. Penelitian ini membahas tentang pembuatan sebuah game bernama SUITCAKE mengunakan Algoritma Linear Congruent Method (LCM) berbasis android dengan software Android Studio. Algoritma Linear Congruent Method (LCM) tersebut merupakan metode pembakitan bilangan acak yang banyak digunakan dalam program komputer. Game ini mengacuh pada permain suit tradional dengan aturan yang sama ditambah dengan beberapa fitur tambahan sehingga membuat permainan suit ini menjadi modern. Berbasis android yang artinya game ini dapat berjalan di plaffom Android dan bisa diunduh pada Playstore.

Kata Kunci: Game, Metode Linear Congruent, Suit, Android

\section{PENDAHULUAN}

Seiring dengan perkembangan zaman teknologi, banyak perubahan dari manual ke sistem baik pun dari tradisional yang dikembangkan ke dalam teknologi. Salah satunya adalah permainan game. Dahulu game dimaikan secara tradisional dan manual seperti permainan catur, kartu dan lainnya

Game adalah salah satu jenis hiburan yang disukai oleh semua orang dari kalangan usia anak-anak, dewasa maupun tua. Sebuah game dibuat dengan maksud dan tujuan agar para pemain menjadi senang, bahagia dan bisa menghilangkan stress dalam kehidupan sehari-harinya.

Banyaknya jumlah dari jenis game yang ada, menyebabkan timbulnya pengelompokan genre dari game. Genre dari game juga akan bertambah mengikuti perkembangan zaman, adapun secara garis besar genre suatu game yaitu genre actions games, genre strategy games serta genre artificial life, board, puzzle dan lainlain.

Salah satu permainan tradisional yaitu, Suten atau yang lebih popular disebut dengan suit merupakan permainan yang sudah ada selama lebih dari puluhan tahun, oleh karena itu diperlukan suatu peremajaan yang dari tradisional kedalam era modern. Dengan memadukan beberapa tampilan dan beberapa fitur tambahan yang akan menjadikan game suit ini menjadi berbeda dari permainan suit klasik.

Game suit yang akan dikembangkan ini merupakan perpaduan dari game klasik dengan adanya fitur tambahan yang lebih menarik, dengan menggunakan algoritma Linear Congruent Method (LCM) yang berfokus pada pengacakan bilangan, sehingga dapat membawa game suit ini menjadi game yang tidak kalah seru dengan game modern zaman sekarang.

Penambahan beberapa fitur yang menarik akan memberikan suasana yang baru bagi pemain. Pembuatan game ini juga ditujukan untuk mencoba menghadirkan game suit yang mungkin sudah jarang dimainkan menjadi kembali menjadi lebih sering dimainkan dimanapun dan kapanpun pemain inginkan.

\section{KERANGKA TEORI}

\section{A. Pengertian Game}

Istilah game yang berasal dari bahasa inggris yang mempunyai arti permainan. Permainan adalah sesuatu yang digunakan untuk bermain yang didalamnya terdapat aturan-aturan tertentu. Seperti yang terdapat pada kamus bahasa indonesia game adalah permainan yang banyak 
digunakan untuk bermain; barang atau sesuatu yang dipermainkan

Game adalah kompetisi antara para pemain yang berinteraksi satu sama lain dengan menggunakan aturanaturan tertentu untuk mencapai tujuan-tujuan tertentu pula. Pada saat permainan game harus ada kompetisi agar pemain lebih seru sehingga Nampak permainan menjadi seru, dimana kompetisi tersebut dapat berwujud menang dan kalah. Pemain harus bisa menemukan strategi atau cara untuk memecahkan masalah sehingga dapat memenangkan game tersebut

Permainan game, adalah sebuah permainan berbentuk multimedia yang di buat semenarik mungkin agar pemain bisa mendapatkan sesuatu sehingga adanya kepuasaan batin. Bermain game lebih sering dimainkan oleh anak-anak, akan tetapi pada zaman sekarang orang dewasa juga suka bermain game dan mengikuti perkembangan game-game yang ada sekarang. Jenis game sangatlah tergantung dari perkembangan zaman. Pada zaman sekarang ini game banyak sekali yang digunakan sesuai dengan selera dan kemampuan kita dalam bermain game. maka permainan dapat digolongkan menjadi dua jenis, yaitu aplikasi permainan 2D (dua dimensi) dan 3D (tiga dimensi) [3].

Terdapat 2(dua) pengertian dari permainan, yaitu [4] :

1) Game merupakan sebuah Permainan yang banyak di sukai oleh kaum mudah zaman sekarang yang murni mencari kesenangan tanpa mencari menang atau kalah

2) Game dapat juga diartikan sebagai permainan diartikan sebagai aktifitas bermain yang dilakukan dalam rangka mencari kesenangan dan kepuasan, namun ditandai pencarian menang-kalah.

Dari istilah pengertian diatas dapat kita simpulkan bahwa game adalah suatu media yang digunakan untuk bermain yang dibangun dengan kecerdasan, metode ataupun teknik tertentu yang dapat memberikan kesenangan atau kepuasan batin.

\section{B. Permainan Suit}

Permainan Suit banyak digunakan di seluruh dunia sebagai alat untuk mngatasi perbedaan pendapat. Dalam sejarahnya yang tidak dapat dipastikan kebenarannya, simbol ini pertama kali digunakan oleh dua Kaisar Jepang kuno dalam menentukan perebutan kekuasaan setelah perundingan yang tidak menemukan mufaklat. Selain batu, kertas, gunting, simbol lain yang menandakan untuk mengatasi perbedaan pendapat adalah suit, suit pertama kali perkenalkan oleh bangsa Indonesia dengan menggunakan jempol, telunjuk dan kelingking. Langkahlangkah permainan suit adalah [5] :
1) Suit dilakukan oleh dua orang pemain.

2) Setiap pemain mengangkatkan salah satu jarinya diantara jempol, telunjuk, atau kelingking secara bersamaan.

3) Mengangkatkan dua buah jari tersebut dengan aturan jempol dan dapat mengalahkan telunjuk, telunjuk mengalahkan kelingking, kelingking mengalahkan jempol.

4) Pemenang adalah pemain yang mempunyai jari yang dapat mengalahkan jari lain milik lawan.

5) Jika pemain mengacungkan jari yang sama maka permainan seri.

\section{Linear Congruent Method (LCM)}

Linear Congruent Method (LCM) adalah metode yang dapat pembangkitan bilangan acak yang banyak digunakan dalam program komputer. LCM diperkenalkan oleh D.H Lehmer pada tahun 1949. Pembangkitan bilangan acak dengan menerapkan metode LCM dapat dilihat di bawah ini [6]. :

$$
X_{n}=\left(a\left(X_{n-1}\right) c\right) \bmod
$$

\section{Dimana :}

$a \quad=$ konstanta pengali

$c \quad=$ konstanta pergeseran

$m$ = konstanta modulus

$X_{n} \quad=$ bilangan acak ke $n$

$X_{n-1}=$ bilangan acak sebelum nya

Syarat-syarat untuk menentukan konstanta dalam LCM adalah sebagai berikut [7] :

1) Konstanta $a$ harus lebih kecil dari $m$.

2) Dalam konstanta $c$ harus berangka ganjil kemudian nialai $m$ bernilai pangkat dua. Tidak boleh nilai dari kelipatan $m$.

3) Untuk $m$ harus bilangan prima.

4) Untuk pertama $X_{0}$ harus merupakan angka integer.

\section{Android}

Android merupakan sebuah sistem operasi untuk perangkat bergerak mobile berbasis linux yang mencakup sistem operasi, middleware dan aplikasi. Aplikasi adroid dapat menyediakan sebuah plafform yang terbuka bagi para pengembang untuk menciptakan aplikasi sendiri. Awalnya, Google Inc. membeli Android Inc. yang merupakan sebuah aplikasi baru yang dapat membuat piranti lunak untuk ponsel atau smartphone. Untuk pengembangan sebuah aplikasi Android maka dibentuklah sebuah Open Handset Alliance, konsorsium dari 34 perusahaan piranti keras, piranti lunak, dan telekomunikasi, termasuk Google, HTC, Intel, Motorola, Qualcomm, T-Mobile dan Nvidia [8]. 


\section{METODOLOGI PENELITIAN}

\section{A. Metode Penelitian}

Metode penelitian yang digunakan dalam penelitian ini adalah metode ekperimen. Dimana dengan metode penelitian ini, peneliti melakukan percobaan tentang berbagai hal, mengamati proses dan menuliskan hasil dari percobaan yang dilakukan serta kemudian hasil dari percobaan tersebut dapat ditarik suatu kesimpulan.

\section{B. Analisa Sistem Baru}

a. Gambaran Umum Game

Dalam penelitian ini, game yang dibuat adalah game dengan nama "SUITCAKE" yang merupakan game bergenre klasik bertemakan tradisional. Permainan ini menggunakan konsep yang sama seperti permainan suit yang aslinya, dimana hasil menang kalahnya ditentukan oleh jari yang dikeluarkan pada saat suit berlangsung dengan aturan yang sudah ada. Aturan-arutan dalam permaian suit yang sudah ada, antara lain adalah :

1) Suit dilakukan oleh dua orang pemain.

2) Setiap pemain mengacungkan salah satu jarinya diantara jempol, telunjuk, atau kelingking secara bersamaan.

3) Menandingkan dua buah jari tersebut dengan aturan yaitu ; jari jempol mengalahkan jari telunjuk, jari telunjuk mengalahkan jari kelingking, dan jari kelingking mengalahkan jari jempol.

4) Pemenang adalah pemain yang mempunyai jari yang dapat mengalahkan jari lain milik lawan.

5) Jika pemain mengacungkan jari yang sama maka harus diulang.

Tugas utama dari game ini adalah mengumpulkan bahan kue, cara mendapatkan bahan-bahan kue tersebut adalah dengan cara mengalahkan musuh yang merupakan komputer. Musuh tersebut akan menentukan pilihan jari yang akan dikeluarkannya secara random dengan mengimplementasikan algoritma Linear Congruent Method (LCM) pada saat suit berlangsung.

Dalam game ini permainan berlangsung dalam lima ronde, pada setiap ronde yang mendapatkan 5 score yang terlebih dahulu adalah pemenangnya, setiap dalam 1 kali adu suit maka pemenang akan mendapatkan 1 score. Jika dalam satu ronde pemain atau player mendapatkan 5 score terlebih dahulu maka player akan dinyatakan menang dan mendapatkan hadiah berupa bahan kue dan bisa masuk keronde selanjutnya untuk mengumpulan bahan kue yang lainnya, begitu seterusnya untuk ronderonde selanjut. Pada saat player mencapai ronde ke lima dan berhasil menang maka iya akan mendapatkan kue.

Game ini dibuat dengan target pemain dari anakanak hingga dewasa dengan kisaran umur 8 tahun keatas. Game ini dibuat dengan menggunakan algoritma Linear Congruent Method (LCM) yang berfokus pada pengacakkan bilangan, dimana player harus bermain dengan musuh yang merupakan komputer yang akan menerapkan algoritma Linear Congruent Method (LCM).

\section{b. Konsep Game}

Penentukan konsep game dalam penelitian ini bertujuan agar game sesuai seperti analisis kebutuhan sudah diinginkan, penentuan konsep ini akan meliputi tema, karakter dan multimedia yang digunakan.

1) Tema, berdasarkan nama game yang diangkat yaitu SUITCAKE adalah membuat permain suit atau suten yang dari tradiosional menjadi modern dengan tampilan dan penambahan fitur.

2) Karakter, karakter yang terdapat dalam game SUITCAKE ini terdiri dari 2 karakter yaitu yang pertama player sebagai pemain (user) dan yang kedua komputer sebagai lawan player saat bermain (cpu).

3) Multimedia, dalam perancangannya meliputi suara (audio) yang akan digunakan sebagai musik dan sound efect yang ada didalam game.

\section{Implementasi LCM}

Algoritma yang digunakan dalam game SUITCAKE ini adalah algortima Linear Congruent Method (LCM). Algortima LCM digunakan untuk mengacak objek yang muncul digalam game agar pengulangan pengacakan yang tidak sama pada game dimainkan.

Pada game SUITCAKE ini terdapat pengacakan objek, pada pengujian ini dicontohkan 50 kali pengacakan, setiap angka akan mewakili jari-jari. Dilakukan 10 kali pengacakan untuk mewakili dari semua pengacakan. Berikut Tabel angka dan hasil pengacakan :

Tabel 1. Pengurutan Angka dan Jari.

\begin{tabular}{|l|l|l|l|l|l|l|l|l|}
\hline 1 & 2 & 3 & 4 & 5 & 6 & 7 & 8 & 9 \\
\hline $\mathrm{J}$ & $\mathrm{T}$ & $\mathrm{K}$ & $\mathrm{J}$ & $\mathrm{T}$ & $\mathrm{K}$ & $\mathrm{J}$ & $\mathrm{T}$ & $\mathrm{K}$ \\
\hline \multicolumn{10}{|c|}{} \\
\hline 11 & 12 & 13 & 14 & 15 & 16 & 17 & 18 & 19 \\
\hline $\mathrm{T}$ & $\mathrm{K}$ & $\mathrm{J}$ & $\mathrm{T}$ & $\mathrm{K}$ & $\mathrm{J}$ & $\mathrm{T}$ & $\mathrm{K}$ & $\mathrm{J}$ \\
\hline \multicolumn{10}{|c|}{} \\
\hline 21 & 22 & 23 & 24 & 25 & 26 & 27 & 28 & 29 \\
\hline $\mathrm{K}$ & $\mathrm{J}$ & $\mathrm{T}$ & $\mathrm{K}$ & $\mathrm{J}$ & $\mathrm{T}$ & $\mathrm{K}$ & $\mathrm{J}$ & $\mathrm{T}$ \\
\hline
\end{tabular}

Dimana :

$\mathrm{J}=$ Jari Jempol

$\mathrm{T}=$ Jari Telunjuk

$\mathrm{K}=$ Jari Kelingking

Penyelesaian :

$X_{n}=\left(a\left(X_{n-1}\right)+c\right) \bmod m$

$a=11$

$c=5$

$X_{0}=1$

$m=29$

$X_{1}=(11 * 1+5) \bmod 29=(16) \bmod 29=16$

$X_{2}=(11 * 16+5) \bmod 29=(181) \bmod 29=7$ 
$X_{3}=(11 * 7+5) \bmod 29=(82) \bmod 29=24$

$X_{4}=(11 * 24+5) \bmod 29=(269) \bmod 29=8$

$X_{5}=(11 * 8+5) \bmod 29=(93) \bmod 29=6$

$X_{6}=(11 * 6+5) \bmod 29=(71) \bmod 29=13$

$X_{7}=(11 * 13+5) \bmod 29=(148) \bmod 29=3$

$X_{8}=(11 * 3+5) \bmod 29=(38) \bmod 29=9$

$X_{9}=(11 * 9+5) \bmod 29=(104) \bmod 29=17$

$X_{10}=(11 * 17+5) \bmod 29=(192) \bmod 29=18$

Dari pengujian algortima Linear Congruent Method (LCM) tersebut, didapat hasil urutan kemunculan 16, 7, 24, 8, 6, 13, 3, 9, 17, 18. Dari contoh tersebut menunjukkan urutan kemunculan yang tidak menunjukkan terjadinya pengulangan.

Tabel 2. Hasil Pengacakan

\begin{tabular}{|l|l|l|l|l|l|l|l|l|l|}
\hline 16 & 7 & 24 & 37 & 3 & 9 & 1 & 18 & 0 & 5 \\
\hline $\mathrm{T}$ & $\mathrm{T}$ & $\mathrm{J}$ & $\mathrm{K}$ & $\mathrm{J}$ & $\mathrm{T}$ & $\mathrm{J}$ & $\mathrm{J}$ & $\mathrm{K}$ & $\mathrm{J}$ \\
\hline
\end{tabular}

\section{Rancangan Interface Game}

1. Rancangan tampilan menu utama

Ketika game dimulai maka ini adalah tampilan awal yaitu tampilan menu dari game SUITCAKE, didalamnya terdapat 3 tombol pilihan menu yaitu play untuk memulai pemainan, about untuk mengetahui cara bermain, dan exit untuk keluar dari game.

\section{TITLE}

\section{About}

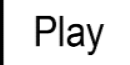

\section{Exit}

Gambar 1 Rancangan Interface Game

\section{2.. Rancangan tampilan gameplay}

Ketika tombol play ditekan akan memasuki tampilan saat bermain game. Didalam bermain game ada objek berupa jari jempol, jari telunjuk, dan jari kelingking, masing-masing dari objek jari tersebut akan dibuat 2 buah yang akan dipilih oleh player dan musuh saat bermain. Dalam tampilan ini juga akan ada informasi ronde, informasi score dan tombol end untuk selesai bermain game dan kembali ke menu utama.

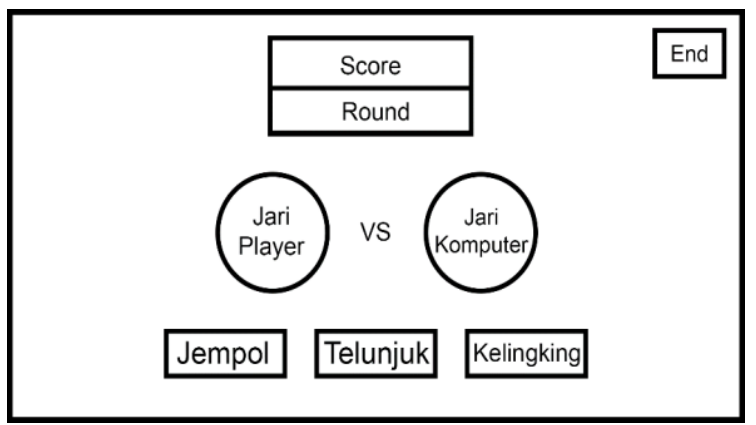

Gambar 2 Rancangan tampilan gameplay

3. Rancangan tampilan jika player menang

Saat player menang ronde, maka akan muncul tampilan yang menyatakan player tersebut menang dan keterangan berupa menang dironde yang ke berapa dan mendapat hadiah apa, serta terdapat 2 buah tombol yaitu tombol untuk kembali ke menu dan untuk lanjut ke ronde berikutnya .

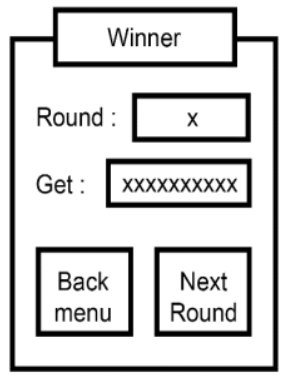

Gambar3 Rancangan tampilan jika player menang

\section{HASIL DAN PEMBAHASAN}

Tampilan menu utama game ini, merupakan halaman yang pertama muncul pada saat game dijalankan. Pada tampilan ini terdapat beberapa tombol seperti About, Play dan Exit. Tampilan menu utama game ini dapat dilihat pada gambar 1

1. Tampilan Menu Utama.

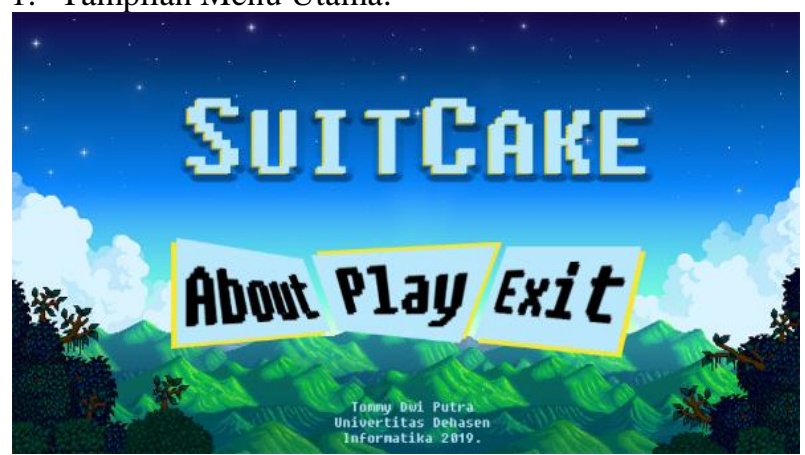

Gambar 1. Tampilan Menu Utama 
2 Tampilan Menu About

Tampilan menu About ini, merupakan tampilan tutorial atau penjelasan bagaimana cara bermain game SUITCAKE. Pada menu ini terdapat tombol back yaitu untuk kembali ke menu utama. Tampilan menu about ini dapat dilihat pada gambar 2 dibahwa ini

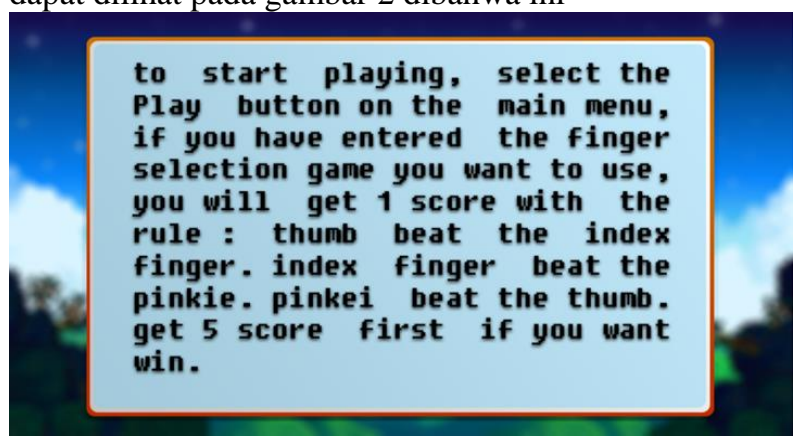

Gambar 2 Tampilan Menu About

4 Tampilan Menu Exit

Tampilan menu Exit ini, merupakan tampilan yang berisi pesan pilihan apakah player ingin keluar dari game SUITCAKE atau tidak. Pada menu ini terdapat dua pilihan yaitu untuk cancel untuk tidak jadi keluar dan oke untuk keluar game. Tampilan menu exit ini dapat dilihat pada gambar 3

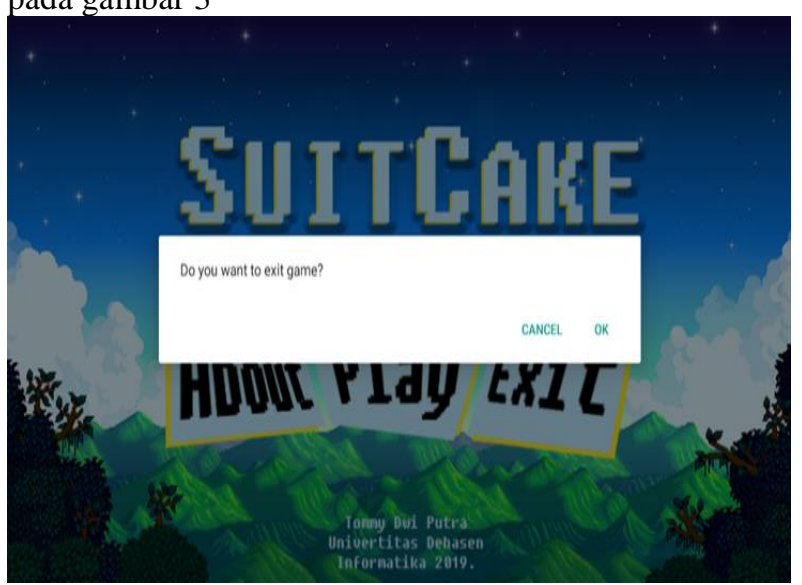

Gambar 3 Tampilan Menu Exit

\section{Tampilan Play game}

Pada menu ini ketika diklik oleh player maka player tersebut akan masuk kedalam game dan bisa langsung memainkannya. Pada saat memainkan game akan terdapat 5 ronde. Tampilan setiap ronde tersebut dapat dilihat pada gambar sampai dengan gambar

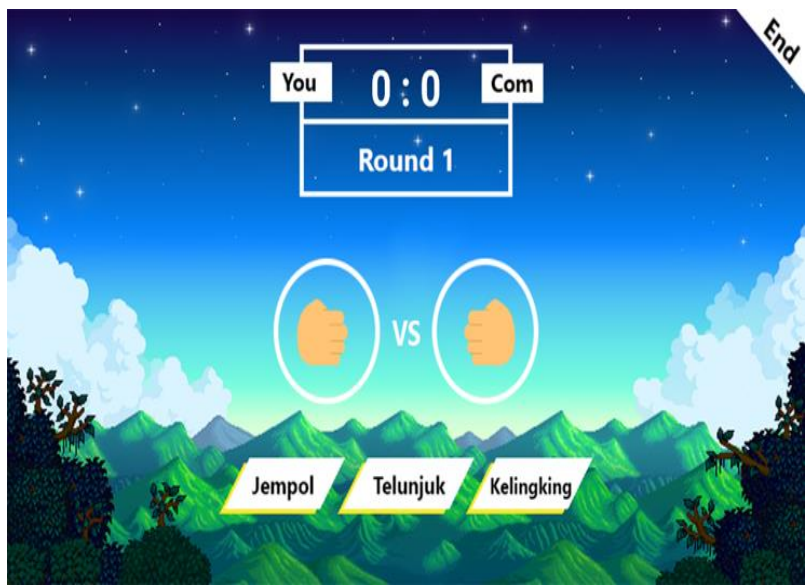

Gambar 4 Tampilan Ronde 1

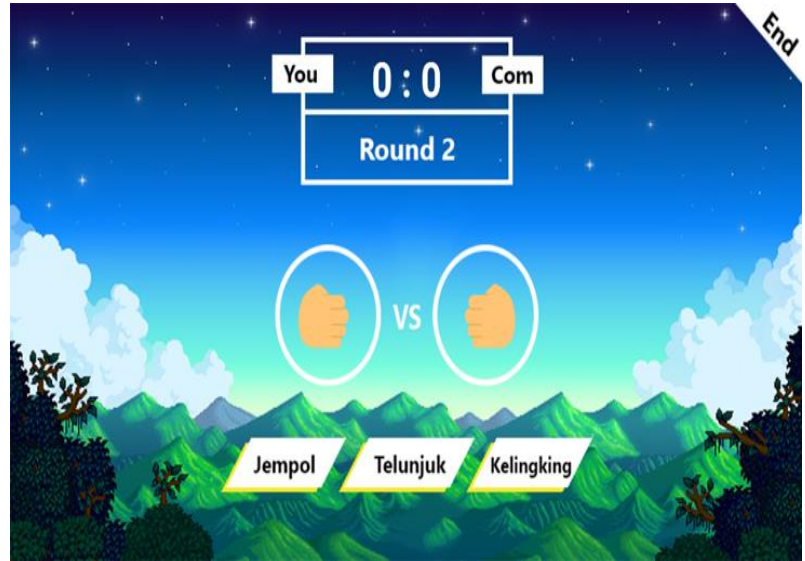

Gambar 5 Tampilan Ronde 2

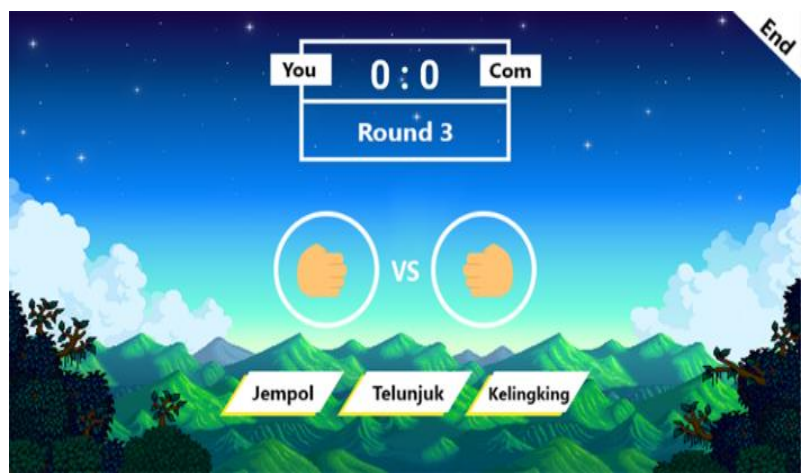

Gambar 6 Tampilan Ronde 3

Pada semua ronde terdapat tampilan yang berisi tombol pilihan yang player pergunakan untuk bermain yaitu tombol jempol, telunjuk, kelingking dan End. Dibagian tengah terdapat gambar jari yang akan keluar sesuai dengan pilihan player dan komputer, dibagian atas terdapat table yang berisi score dan keterangan ronde. 


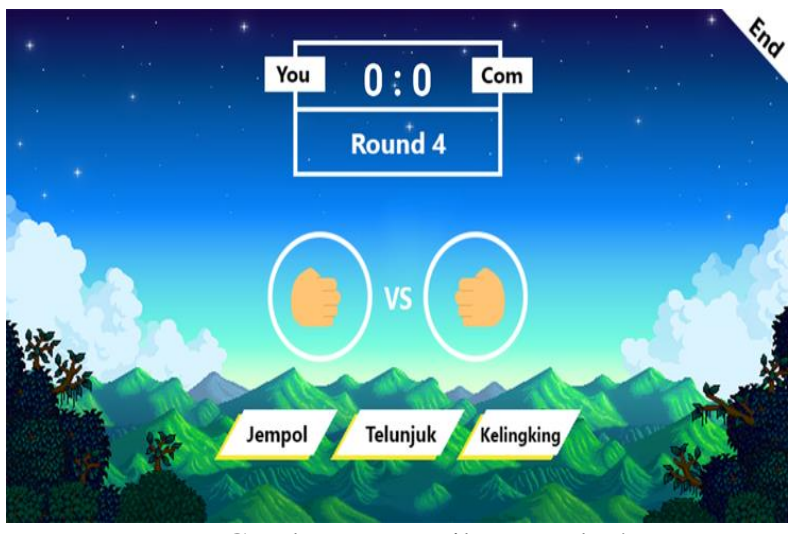

Gambar 7 Tampilan Ronde 4

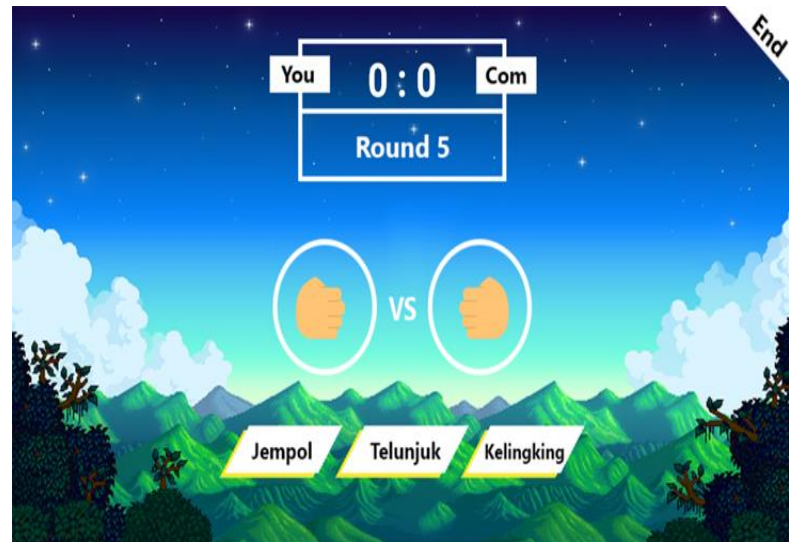

Gambar 8 Tampilan Ronde 5

\section{Tampilan game over}

Tampilan game over ini akan keluar jika player kalah melawan komputer. Tampilan ini dapat dilihat pada gambar dibahwa ini.

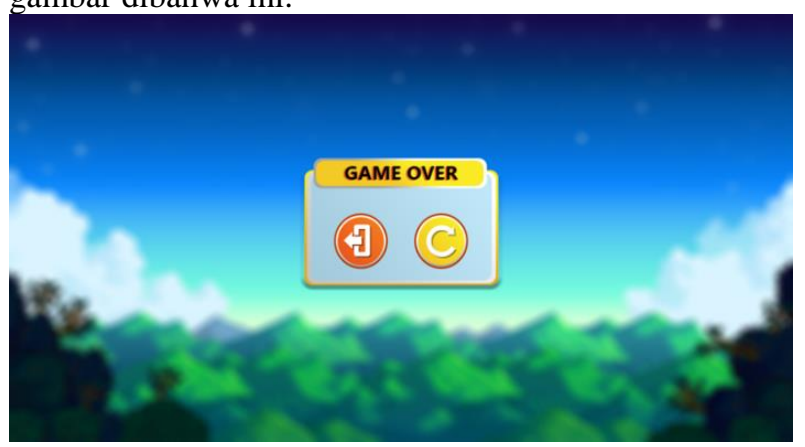

Gambar 9 Tampilan game over

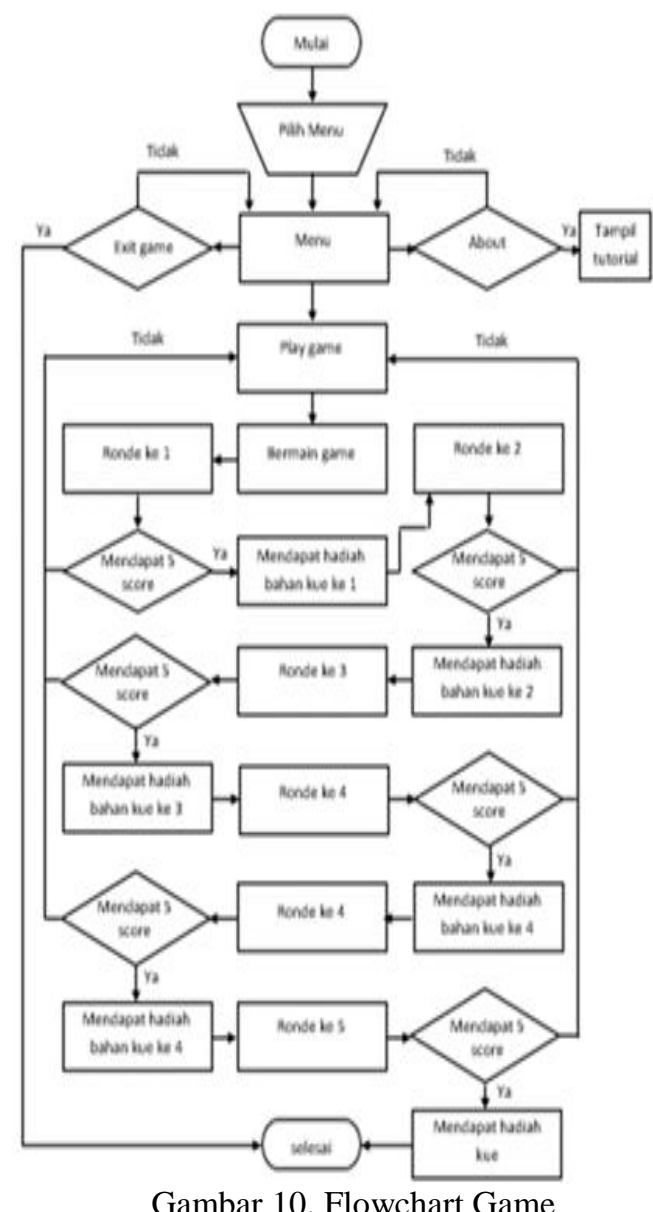

Tabel 3. Pengujian Black Box

\begin{tabular}{|c|c|l|l|}
\hline No. & $\begin{array}{l}\text { Tombol } \\
\text { ditekan }\end{array}$ & \multicolumn{1}{|c|}{ Hasil } & \multicolumn{1}{|c|}{ Ket } \\
\hline 1. & PIaI & Mulai game & Valid \\
\hline 2. & Alnut & $\begin{array}{l}\text { Menampilkan } \\
\text { about }\end{array}$ & Valid \\
\hline 3. & ExI & Keluar game & Valid \\
\hline 4. & Jempol & Muncul jempol & Valid \\
\hline 5. & Telunjuk & Muncul telunjuk & Valid \\
\hline 6. & Kelingking & Muncul kelingking & Valid \\
\hline 7. & Sy & Kembali ke menu & Valid \\
\hline 8. & & Kembali ke menu & Valid \\
\hline 9. & & $\begin{array}{l}\text { Masuk ronde } \\
\text { berikutnya }\end{array}$ & Valid \\
\hline 10. & & Bermain lagi & Valid \\
\hline
\end{tabular}




\begin{tabular}{|c|l|l|l|}
\hline No. & \multicolumn{1}{|c|}{$\begin{array}{c}\text { Tombol } \\
\text { ditekan }\end{array}$} & \multicolumn{1}{|c|}{ Hasil } & Ket \\
\hline 11. & $\begin{array}{l}\text { Jika tombol } \\
\text { back ditekan }\end{array}$ & Kembali & Valid \\
\hline 12. & $\begin{array}{l}\text { Jika player } \\
\text { mendapat 5 } \\
\text { score }\end{array}$ & Menang & Valid \\
\hline 13. & $\begin{array}{l}\text { Jika komputer } \\
\text { mendapat 5 } \\
\text { score }\end{array}$ & Kalah & Valid \\
\hline 14. & $\begin{array}{l}\text { Jika melihat } \\
\text { notifikasi bar }\end{array}$ & $\begin{array}{l}\text { Muncul notifikasi } \\
\text { bar }\end{array}$ & Valid \\
\hline 15. & $\begin{array}{l}\text { Jika tombol } \\
\text { home ditekan }\end{array}$ & Kembali ke home & Valid \\
\hline 16. & $\begin{array}{l}\text { Jika tombol } \\
\text { recent ditekan }\end{array}$ & Muncul recent app \\
\hline
\end{tabular}

\section{KESIMPULAN}

Berdasarkan hasil dan pembahasan serta hasil pengujian maka dapat diambil beberapa kesimpulan, yaitu :

1) Algoritma Linear Congruent Method (LCM) dapat diterapkan dan berjalan sebagaimana mestinya dalam game SUITCAKE berbasis android.

2) Game SUITCAKE ini layak digunakan berdasarkan dari hasil pengujian kuesioner yang telah dibagikan oleh 10 orang responden.

\section{DAFTAR PUSTAKA}

[1] https://kbbi.web.id/main.

[2] A.S. Sadiman. "Media Pemdidikan : Pengertian, Pengembangan dan Pemanfaatannya". Rajawali Pers. Jakarta. 2010.

[3] P.A. Yudhanto. "Perancangan Promosi Produk EduGames Melalui Event". Universitas Komputer Indonesia. Bandung. 2010.

[4] A. Ismail. "Education Games". Pro-U Media. Yogyakarta. 2009.

[5] B. A. Saputro. "Grup Permutasi Siklis Dalam Permainan Suit". STKIP Siliwangi. Bandung. 2012.

[6] Mesran. "Pemanfaatan Mobile Device pada Ujian Matakuliah Menetapkan Linear Congruent Method (LCM) Berbasis Android". STMIK Budi Darma Medan. 2016.

[7] J. T. Kikay. "Pengantar Sistem Simulasi". ANDI. Yogyakarta. 2004.

[8] N. Safaat. "Pemrograman Aplikasi Mobile Smartphone dan Table PC Berbasis Android". Informatika. Bandung. 2012. 